\title{
Akt3 is a target of miR-29c-3p and serves an important function in the pathogenesis of congenital heart disease
}

\author{
TAO CHEN $^{1 *}$, SHU-JUN LI ${ }^{2 *}$, BIN CHEN $^{1}$, QIONG HUANG ${ }^{1}$, XIANG-YING KONG ${ }^{1}$, \\ CHEN SHEN $^{1}$, HAI-TAO GU ${ }^{1}$ and XIAO-WEI WANG ${ }^{1}$ \\ ${ }^{1}$ Department of Cardiothoracic Surgery, The First Affiliated Hospital of Nanjing Medical University, Nanjing, Jiangsu 210029; \\ ${ }^{2}$ Department of Pediatrics, Children's Hospital of Anhui Medical University, Hefei, Anhui 230000, P.R. China
}

Received February 8, 2018; Accepted October 9, 2018

DOI: $10.3892 /$ ijmm.2018.4008

\begin{abstract}
Our previous studies identified that the expression of microRNA-29c (miR-29c-3p) was significantly increased in the serum of pregnant women carrying fetuses with congenital heart disease (CHD) compared with in that of normal pregnant women. However, the mechanism by which miR-29c-3p affects development of the embryonic heart remained unclear. The aim of the present study was to investigate the effect and potential molecular mechanism of miR-29c-3p overexpression on P19 cell proliferation, apoptosis and differentiation. miR-29c-3p-overexpression and protein kinase $\mathrm{B} \gamma(\mathrm{Akt} 3)-\mathrm{knockdown}$ cell lines were constructed using transfection technology. The function of miR-29c-3p and Akt 3 in cardiomyocyte development was investigated by determining the proliferation, apoptosis and differentiation of P19 cells, which can differentiate into cardiomyocytes induced by dimethylsulfoxide. Bioinformatic analysis and luciferase assays were performed to explore the association between Akt3 and miR-29c-3p. The results of the present study revealed that miR-29c-3p overexpression and Akt3 knockdown suppressed proliferation, and promoted apoptosis and differentiation in P19 cells. Akt 3 was also demonstrated to be a target of miR-29c-3p. Therefore, overexpression of miR-29c-3p may inhibit proliferation, and promote apoptosis and differentiation in P19 cells by inhibiting the expression of Akt3. miR-29c-3p may be a potential therapeutic target for the treatment of CHD.
\end{abstract}

Correspondence to: Dr Hai-Tao Gu or Dr Xiao-Wei Wang, Department of Cardiothoracic Surgery, The First Affiliated Hospital of Nanjing Medical University, 300 Guangzhou Road, Nanjing, Jiangsu 210029, P.R. China

E-mail: guhaitao65@163.com

E-mail: wangxiaowei@njmu.edu.cn

${ }^{*}$ Contributed equally

Key words: microRNA-29c, P19 cell, proliferation, apoptosis, differentiation, protein kinase $\mathrm{B} \gamma$

\section{Introduction}

Congenital heart disease (CHD) is the most common congenital defect globally (1-3). The incidence of neonatal morbidity is $0.8-1.0 \%$ (4), and $30 \%$ of newborns with CHD succumb without radical treatment. Therefore, further investigation into CHD prevention and treatment is of vital importance. The heart is the first organ to become functional during embryological development. Its developmental process is complex and disturbed easily, involving the precise regulation of a number of gene signals. The minor errors during development can lead to the lesion of the atrium, ventricle, valve and other heart structures, which results in the occurrence of CHD.

microRNAs (miRNAs/miRs) are a type of non-coding single-stranded RNA of 22 nucleotides in length, which have important regulatory functions within cells (5). In recent years, miRNAs have received increasing attention in the field of heart development (6-8). We previously identified that miR-29c-3p in serum from patients with CHD, and that its expression was significantly increased in the serum of pregnant women carrying fetuses with CHD compared with in that of normal pregnant women (9). Although miR-29c-3p may be associated with the development of CHD, the majority of current miR-29c-3p research focuses on cancer, with few studies describing its function in heart development. Shu et al (10) identified that the expression of miR-29c-5p was significantly downregulated in gallbladder carcinoma and was markedly associated with lymph node metastasis. Han et al (11) identified that loss of miR-29c-3p expression was an early event in the initiation of gastric carcinogenesis. Other studies have revealed that miR-29c-3p was associated with lung cancer (12), nasopharyngeal carcinoma (13), acute myeloid leukemia (14) and breast cancer (15).

The phosphoinositide 3-kinase (PI3K)/protein kinase B $\gamma$ (Akt3) signaling pathway serves an important function in cardiac development and disease occurrence. The PI3K/Akt3 signaling pathway is involved in heart ischemia/reperfusion injury (16), myocardial hypertrophy (17) and myocardial cell reshaping (18), but it can also affect normal heart development (19) by regulating cardiac progenitor cell proliferation. As an important factor in the PI3K/Akt3 signaling pathway, Akt3 was selected for investigation in the present study.

The $\mathrm{P} 19$ cell line is derived from the $\mathrm{CH} 3 / \mathrm{He}$ mouse teratocarcinoma and can differentiate into three germ layers: 
Endodermal phenotype, mesodermal phenotype and neuronal phenotype (20). At low concentrations of dimethylsulfoxide (DMSO), P19 cells aggregate and are induced to differentiate into cardiomyocytes (21-24). Therefore, P19 cells are used widely as a myocardial cell model of cardiomyocyte differentiation in vitro $(25,26)$.

The aim of the present study was to investigate the function of miR-29c-3p and Akt3 in the occurrence of CHD. Transfection technology was used to research the effect of miR-29c-3p overexpression on the function of P19 cells, which are a classic model of embryonic heart development.

\section{Materials and methods}

Cell culture and differentiation. Murine P19 embryonal carcinoma cells were obtained from Nanjing Maternity and Child Health Care Hospital Affiliated to Nanjing Medical University (Jiangsu Province, China). Cells were cultured in $\alpha$-minimal essential medium with $10 \%$ fetal bovine serum (both from Gibco; Thermo Fisher Scientific, Inc., Waltham, MA, USA), $100 \mathrm{U} / \mathrm{ml}$ penicillin and $100 \mu \mathrm{g} / \mathrm{ml}$ streptomycin (Hyclone; GE Healthcare Life Sciences, Logan, UT, USA) at $37^{\circ} \mathrm{C}$ in an incubator containing $5 \% \mathrm{CO}_{2}$. To induce P19 cell differentiation, DMSO (Sigma-Aldrich; Merck KGaA, Darmstadt, Germany) was added to the culture medium at a final concentration of 1.0\% (27-29). P19 cells aggregated over the following 4 days to form embryoid bodies (EBs), during which time the medium was replenished every $24 \mathrm{~h}$. On day 4 the EBs were transferred into a 6-well plate and cultured in DMSO-free medium to allow adherent proliferation of P19 cells. The culture medium was refreshed every $48 \mathrm{~h}$ during the ensuing differentiation. The P19 cells were confirmed to be successfully induced into cardiomyocytes when the beating cardiomyocytes were observed under a microscope. Images of the EBs and differentiated cell patches were captured microscopically using a Primovert ZM300FL fluorescence microscope (Carl Zeiss AG, Oberkochen, Germany).

Transfection of miR-29c-3p mimic and small interfering RNA (siRNA). At 1 day before transient transfection, P19 cells were plated in 6-well plates at a density of $2 \times 10^{4}$ cells/well and incubated at $37^{\circ} \mathrm{C}$. A miR-29c-3p mimic (forward, 5'-UAGCAC CAUUUGAAAUCGGUUA-3'; reverse, 5'-UAACCGAUU UCAAAUGGUGCUA-3'; 100 nM) synthesized by Guangzhou RiboBio Co., Ltd. (Guangzhou, China) was used to produce miR-29c-3p-overexpressing cells, $100 \mathrm{nM}$ si-Akt3 (5'-GCT CATTCATAGGCTATAA-3'; Guangzhou RiboBio Co., Ltd.) was transfected for Akt 3 knockdown, whereas scrambled oligonucleotides served as negative controls. Transfection of cells at $30-40 \%$ confluence was achieved using Lipofectamine ${ }^{\circledR} 3000$ (Invitrogen; Thermo Fisher Scientific, Inc.), according to the manufacturer's protocol. Briefly, two mixtures were prepared separately: Mixture A [125 $\mu$ l Opti-MEM (Gibco; Thermo Fisher Scientific, Inc.) and $5 \mu 1$ Lipofectamine 3000] and mixture B (125 $\mu \mathrm{l}$ Opti-MEM and $10 \mu \mathrm{lmimic})$. si-Akt3 and negative control mixtures were prepared in the same manner. The two mixtures were left to stand at room temperature for $5 \mathrm{~min}$, then mixed and left for a further $30 \mathrm{~min}$. The mixture was then added to each well of the 6-well plate. At $48 \mathrm{~h}$ after transfection, the transfection efficiency was determined.
miR-29c-3p fluorescence was determined using fluorescence microscopy, whereas miR-29c-3p and Akt 3 mRNA expression were determined using the reverse transcription-quantitative polymerase chain reaction (RT-qPCR), and Akt3 protein levels were determined by western blotting.

Cell proliferation and cell cycle assays. A Cell Counting Kit-8 (CCK-8; Dojindo Molecular Technologies, Inc., Kumamoto, Japan) assay was used to determine the proliferation rate of P19 cells. P19 cells at a density of $1 \times 10^{3}$ cells/well were plated in 96-well plates. Following incubation for $24 \mathrm{~h}$, transfection of the miR-29c-3p mimic/si-Akt3/negative control was performed as aforementioned. Following a further $24 \mathrm{~h}, 10 \mu \mathrm{l}$ CCK-8 reagent was added to each well, according to the manufacturer's protocol, and the cells were maintained at $37^{\circ} \mathrm{C}$ for $2 \mathrm{~h}$ under $5 \% \mathrm{CO}_{2}$. The cell proliferation was determined by measuring the optical density (OD) at $450 \mathrm{~nm}$ using a Multiskan GO microplate reader (Thermo Fisher Scientific, Inc.). Cells were monitored every $24 \mathrm{~h}$ over the following 4 days.

For cell cycle analysis, P19 cells were plated in 6-well plates at a density of $2 \times 10^{4}$ cells/well and were transfected as aforementioned after $24 \mathrm{~h}$. When the cells had adhered, trypsin digestion was used to harvest them at 24-h intervals. Pelleted cells were washed twice with PBS at $4^{\circ} \mathrm{C}$, and resuspended in $70 \%$ ethanol at $-20^{\circ} \mathrm{C}$ overnight. The cells were then washed once with PBS and resuspended in $300 \mu 1$ DNA staining solution and $3 \mu \mathrm{l}$ permeabilization solution [Cell Cycle Staining kit; Multisciences (Lianke) Biotechnology LLC, Hangzhou, China] for $20 \mathrm{~min}$ at room temperature. Subsequently, cells were analyzed by flow cytometry using a FACSCalibur (BD Biosciences, Franklin Lakes, NJ, USA) instrument, and the proportion of cells in each phase of the cell cycle was determined according to the DNA content using FlowJo software (version 7.6.1; Tree Star, Inc., Ashland, OR, USA).

Cell apoptosis. $\mathrm{P} 19$ cells were plated in 6-well plates at a density of $2 \times 10^{4}$ cells/well and were transfected as aforementioned after $24 \mathrm{~h}$. After $48 \mathrm{~h}$, the medium was removed and $0.5 \mathrm{ml}$ paraformaldehyde was added to each well for $10 \mathrm{~min}$, then removed. Following washing with PBS, cells were stained with $0.5 \mathrm{ml}$ Hoechst 33258 (Beyotime Institute of Biotechnology, Haimen, China) per well for $5 \mathrm{~min}$. Fluorescence was analyzed using a fluorescence microscope at a magnification of x100.

Flow cytometry was used to evaluate the apoptotic status of P19 cells. Cells were transfected as aforementioned, harvested using trypsin and washed twice in ice-cold PBS. Cells were centrifuged at $100 \mathrm{xg}$ for $5 \mathrm{~min}$ at $4^{\circ} \mathrm{C}$, resuspended in $200 \mu \mathrm{l}$ $1 \mathrm{X}$ binding buffer [10 $\mathrm{mM}$ 4-(2-hydroxyethyl)-1-piperazineethanesulfonic acid, $140 \mathrm{mM} \mathrm{NaCl}, 1 \mathrm{mM} \mathrm{MgCl} 2,5 \mathrm{mM}$ $\mathrm{KCl}$ and $2.5 \mathrm{mM} \mathrm{CaCl}_{2}$ ], and $5 \mu 1$ Annexin V-fluorescein isothiocyanate and $5 \mu \mathrm{l}$ propidium iodide (Cell Cycle Staining kit) were added immediately. Samples were analyzed using flow cytometry.

RNA isolation and extraction. When P19 cells achieved 80-90\% confluence, total RNA was isolated using an RNAiso Plus kit (Takara Bio, Inc., Otsu, Japan). RNA concentrations were determined using a NanoDrop ND-1000 spectrophotometer (NanoDrop Technologies; Thermo Fisher Scientific, Inc., Wilmington, DE, USA). 
Table I. Primer sequences for the quantitative polymerase chain reaction.

\begin{tabular}{lll}
\hline Gene & \multicolumn{1}{c}{ Forward primer (5'-3') } & \multicolumn{1}{c}{ Reverse primer (5'-3') } \\
\hline GAPDH & AACTTTGGCATTGTGGAAGG & CACATTGGGGGTAGGAACAC \\
Akt3 & TGGCGGAGAGCTGTTTTCC & GGCCATCCTTATCTAGCATCAAA \\
Bax & AGACAGGGGCCTTTTTGCTAC & AATTCGCCGGAGACACTCG \\
Bcl-2 & ATGCCTTTGTGGAACTATATGGC & GGTATGCACCCAGAGTGATGC \\
cTnT & GGAGTACGAGGAGGAACAGG & GTCCACTCTCTCTCCATCGG \\
$\alpha \mathrm{MHC}$ & ACCAACCTGTCCAAGTTCCG & GTCGTGCATCTTCTTGGCAC \\
Mef2c & TGTCCAGCCATAACAGTTTGG & CCTTGTGAACATGAAGTCCTCTT \\
GATA4 & CCAACTGCCAGACTACCAC & GGACCAGGCTGTTCCAAGA
\end{tabular}

Akt3, protein kinase B $\gamma$; Bcl-2, B-cell lymphoma-2; Bax, Bcl-2-associated X protein; cTnT, cardiac troponin T; $\alpha$ MHC, $\alpha$-myosin heavy chain; Mef2c, myocyte enhancer factor 2c; GATA4, GATA-binding protein 4.

Determination of $m i R-29 c-3 p$ expression by $R T-q P C R$. miR-29c-3p was converted into cDNA using a PrimeScript ${ }^{\mathrm{TM}}$ RT Reagent kit (Takara Bio, Inc.), according to the manufacturer's protocol, from $1 \mu \mathrm{g}$ total RNA isolated as aforementioned. RT-qPCR was performed using an ABI 7500 Fast real-time PCR cycler (Applied Biosystems; Thermo Fisher Scientific, Inc.). U6 was used as an internal control. The primers for miR-29c-3p and U6 were purchased from Realgene (Nanjing, China). Amplification was performed with the $\mathrm{SYBR}^{\circledR}$ Premix Ex Taq ${ }^{\mathrm{TM}}$ (Takara Bio, Inc.), according to the manufacturer's protocol. Primer sequences were as follows: $\operatorname{miR}-29 \mathrm{c}-3 \mathrm{p}$ forward, 5'-GCGCGCGTAGCACCATTTGAA AT-3'; miR-29c-3p reverse, 5'-ATCCAGTGCAGGGTCCGAGG-3'; U6 forward, 5'-CTCGCTTCGGCAGCACATATACT-3'; U6 reverse, 5'-ACGCTTCACGAATTTGCGTGTC-3'; and RT primer, 5'-GTCGTATCCAGTGCAGGGTCCGAGGTATTC GCACTGGATACGACTAACCG-3'.

RT-qPCR analysis of Akt3, B-cell lymphoma-2 (Bcl-2), Bcl-2associated $X$ protein (Bax), $\alpha$-myosin heavy chain (aMHC), cardiac troponin $T(c \operatorname{Tn} T)$, myocyte enhancer factor $2 c$ (Mef $2 c)$ and GATA-binding protein 4 (GATA4) transcripts. RT of $1 \mu \mathrm{g}$ RNA isolated from P19 cells into cDNA was performed using the PrimeScript ${ }^{\mathrm{TM}}$ RT Reagent kit, according to the manufacturer's protocol. qPCR was performed using a SYBR-Green kit (Takara Bio, Inc.)-based detection system. The thermocycling conditions (30) were as follows: $95^{\circ} \mathrm{C}$ for $180 \mathrm{sec}$, then 40 cycles of $95^{\circ} \mathrm{C}$ for $10 \mathrm{sec}, 60^{\circ} \mathrm{C}$ for $30 \mathrm{sec}, 70^{\circ} \mathrm{C}$ for $10 \mathrm{sec}$; melting curve analysis: $95^{\circ} \mathrm{C}$ for $15 \mathrm{sec}, 60^{\circ} \mathrm{C}$ for $60 \mathrm{sec}$ and $95^{\circ} \mathrm{C}$ for $15 \mathrm{sec}$. Results were analyzed using the $2^{-\Delta \Delta \mathrm{Cq}}$ method (31). GAPDH primers were used for normalization. All primers were purchased from Realgene (Table I).

Western blot analysis. Protein was extracted from P19 cell samples using the Whole Cell Lysis assay (Nanjing KeyGen BioTech Co., Ltd., Nanjing, China), and protein concentrations were determined using the Bicinchoninic Acid Protein assay kit (Beyotime Institute of Biotechnology). Subsequently, $50 \mu \mathrm{g}$ denatured proteins were separated by SDS-PAGE (10\% gels) and transferred onto polyvinylidene fluoride membranes (Bio-Rad Laboratories, Inc., Hercules, CA, USA). The membranes were then blocked at room temperature with $5 \%$ bovine serum albumin suspended in Tris-buffered saline containing $0.1 \%$ Tween-20 (TBST) for $2 \mathrm{~h}$, washed in TBST, and incubated at $4^{\circ} \mathrm{C}$ overnight with monoclonal rabbit anti-mouse Bax antibody (1:1,000 dilution; cat. no. WL01637; Wanleibio Co., Ltd., Shanghai, China), monoclonal rabbit anti-mouse Bcl-2 antibody (1:1,000 dilution; cat. no. WL01556; Wanleibio Co. Ltd.), monoclonal rabbit anti-mouse Akt3 antibody (1:500 dilution; cat. no. 4059; Biogot Technology, Co., Ltd., Nanjing, China) or monoclonal mouse anti-mouse $\beta$-actin antibody (1:2,000 dilution; cat. no. ab8226; Abcam, Cambridge, UK). The membranes were washed with TBST and incubated with horseradish peroxidase-conjugated polyclonal goat anti-rabbit immunoglobulin $\mathrm{G}(\mathrm{IgG})$ secondary antibody [1:3,000 dilution; cat. no. 85-11-4839-81; Multisciences (Lianke) Biotech Co., Ltd.] or horseradish peroxidase-conjugated polyclonal goat anti-mouse IgG secondary antibody (1:3,000 dilution; cat. no. 70-GAM001; Multisciences (Lianke) Biotech Co., $\mathrm{Ltd}$.) for $2 \mathrm{~h}$ at room temperature. Following a further three washes with TBST, the blots were visualized using Enhanced Chemiluminescence Plus reagents [Multisciences (Lianke) Biotech Co., Ltd.]. For western blot analysis, $\beta$-actin was used as an internal control. Protein expression levels were quantified using ImageJ2x software (version 2.1.4.5; Rawak Software, Inc., Stuttgart, Germany).

Luciferase reporter assays. To further investigate the miR-29c-3p regulatory mechanisms in cardiac development, miRTarBase (www.mirbase.org), TargetScan (www.targetscan. org) and miRNApath (snf-515788.vm.okeanos.grnet.gr) were used to predict potential target genes. Akt3 was identified as a likely target of miR-29c-3p, as the same result was obtained across all platforms. To validate this prediction, functional luciferase assays were performed. To determine whether miR-29c-3p was able to bind to the 3'-untranslated region (UTR) of Akt3, wild-type (wt), Akt3 3'-UTR sequence (Pgl3-Akt3 3'-UTR-wt) and pGL3-Akt3 3'-UTR-mutant (mut) sequence (comprising the Akt3 3'-UTR sequence with a number of mutations) luciferase reporter plasmids were used (Promega Corporation, Madison, WI, USA). A total of $1 \times 10^{5}$ cells was seeded in triplicate in 48 -well plates for $24 \mathrm{~h}$, then transfected with $100 \mathrm{ng}$ luciferase reporter plasmid and $100 \mathrm{nM}$ miRNA 
A
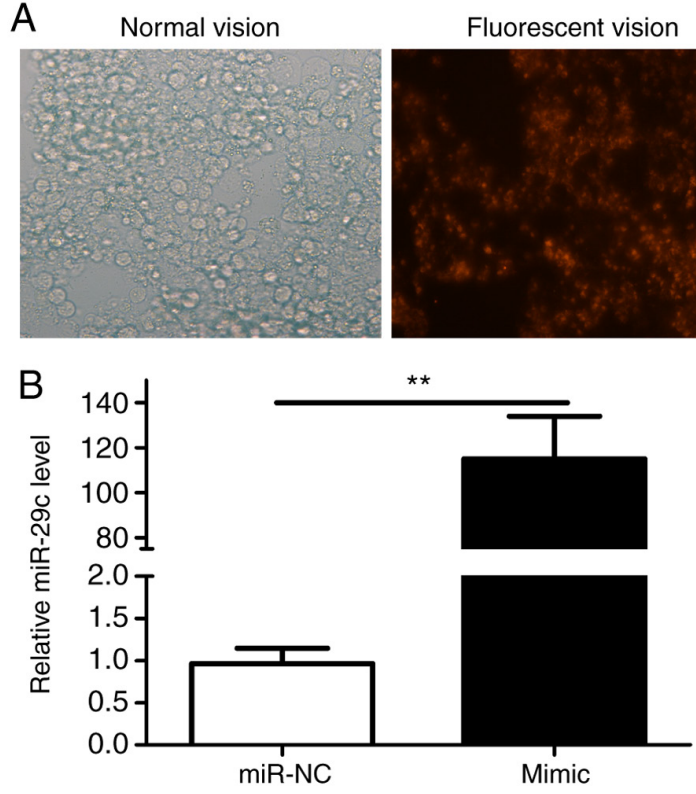

Figure 1. Transfection efficiency of miR-29c-3p mimic. (A) miR-29c-3p mimic was successfully transfected and the expression was observed using fluorescence microscopy (magnification, x100). (B) miR-29c-3p expression in P19 cells with the miR-29c-3p mimic $(n=3) .{ }^{* *} \mathrm{P}<0.01$ vs. miR-NC. miR, microRNA; NC, negative control.

using Lipofectamine 3000. At $48 \mathrm{~h}$ after transfection, the cells were lysed and luciferase activity was assayed using a Dual-Luciferase Reporter assay system (Promega Corporation). The following primers were used: mmu-miR-29c-3p, 5'-UAG CACCAUUUGAAAUCGGUUA-3'; Akt3 wt, 5'-TTCAGA TTAACCCTTTGGTGCTA-3'; and Akt3 mut, 5'-TTCAGA TTAACCCTTACCACGAT-3'.

Statistical analysis. Results are presented as the mean \pm standard deviation. The statistical significance of the results was analyzed using one-way analysis of variance, and the least significant difference post-hoc test was used for further multiple comparisons. P-values were two-sided, and $\mathrm{P}<0.05$ was considered to indicate a statistically significant difference. Analyses were performed using SPSS software (version 18.0; SPSS, Inc., Chicago, IL, USA).

\section{Results}

Overexpression of $\mathrm{miR}-29 \mathrm{c}-3 p$ suppresses $P 19$ cell proliferation and promotes apoptosis. The expression of miR-29c-3p following the transfection of P19 cells with the miR-29c-3p mimic was analyzed by fluorescence microscopy (Fig. 1A) and was revealed to be significantly increased (Fig. 1B). The CCK- 8 assay indicated that the standard deviation of the OD value at each point was small, and that the cells grew exponentially. Differences in proliferation rates emerged at $48 \mathrm{~h}$ post-transfection, and became obvious at $72 \mathrm{~h}$. At $72 \mathrm{~h}$, the OD value of the miR-29c-3p-overexpression group was significantly decreased compared with that of control cells (Fig. 2). Flow cytometric results (Fig. 3A and B) indicated that the proportion of cells in $\mathrm{S}$ phase was significantly decreased in miR-29c-3p-overexpressing cells compared with in control cells (Fig. 3C).

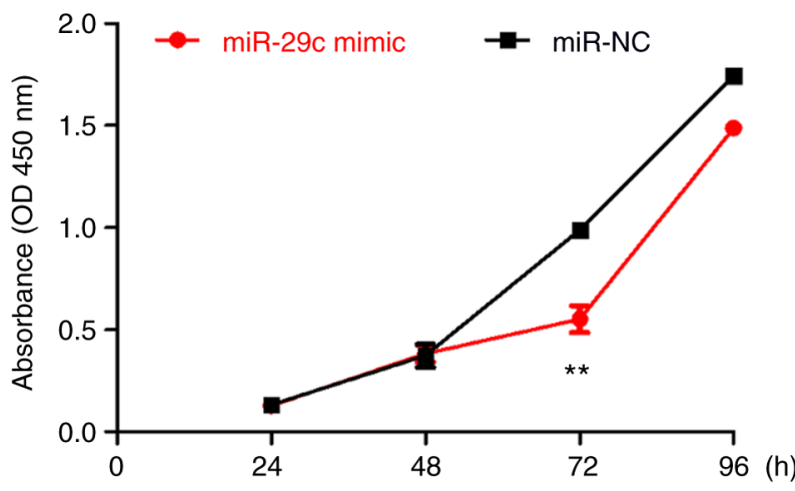

Figure 2. Cell proliferation was continuously monitored for $96 \mathrm{~h}$ using the cell counting kit- $8(\mathrm{n}=3) .{ }^{* *} \mathrm{P}<0.01$ vs. miR-NC. miR, microRNA; NC, negative control; OD, optical density.

Hoechst staining revealed an increased number of apoptotic cells in the miR-29c-3p-overexpression group compared with in the control group. Furthermore, the nuclei of these cells appeared as fragmented or dense spots, respectively, under a fluorescence microscope (Fig. 4A and B). To verify the Hoechst staining results, flow cytometry was performed (Fig. 5A and B). At $48 \mathrm{~h}$, the apoptotic rate of miR-29c-3p-overexpressing cells was significantly increased compared with that of the negative control cells (Fig. 5C). Furthermore, RT-qPCR (Fig. 6A) and western blotting (Fig. 6B and C) indicated that expression of the anti-apoptotic Bcl-2 was similar between the two groups, but that of the pro-apoptotic Bax was increased in the miR-29c-3p-overexpressing cells compared with in the negative control cells, a difference that was determined to be significant.

miR-29c-3p decreases Akt3 expression by targeting the Akt3 3'-UTR in P19 cells. Bioinformatics analysis was used to identify additional novel targets of miR-29c-3p, and it was identified that miR-29c-3p was able to bind to the 3'-UTR of Akt3 mRNA. Therefore, it is possible that miR-29c-3p inhibits Akt3 by binding directly to its 3'-UTR (Fig. 7A). Luciferase reporter assays indicated that P19 cells co-transfected with plasmids carrying wild-type Akt3 3'-UTR and miR-29c-3p mimic exhibited significantly decreased activity levels compared with controls, but that there was no difference in cells carrying the mutant construct (Fig. 7B). Western blotting indicated that miR-29c-3p overexpression in P19 cells suppressed Akt3 protein expression (Fig. 7C and D). These results support the post-transcriptional regulation of Akt 3 by miR-29c-3p.

Knockdown of Akt3 inhibits proliferation and cell cycle progression of P19 cells. Akt3 mRNA expression was identified to be significantly decreased $48 \mathrm{~h}$ after transient transfection (Fig. 8A) and the protein level of Akt3 decreased similarly (Fig. 8B and C). Continuous 72-h monitoring using the CCK-8 assay determined that proliferation was decreased in the Akt3-knockdown group compared with that of the control group (Fig. 9). At $48 \mathrm{~h}$, the proliferation rate of P19 cells reached its maximum. In the next phase, the proliferation rate of si-Akt3 and si-NC decreased possibly because of the contact inhibition mechanism. Flow cytometry revealed an increased proportion of $G_{1}$ phase cells and a decreased 

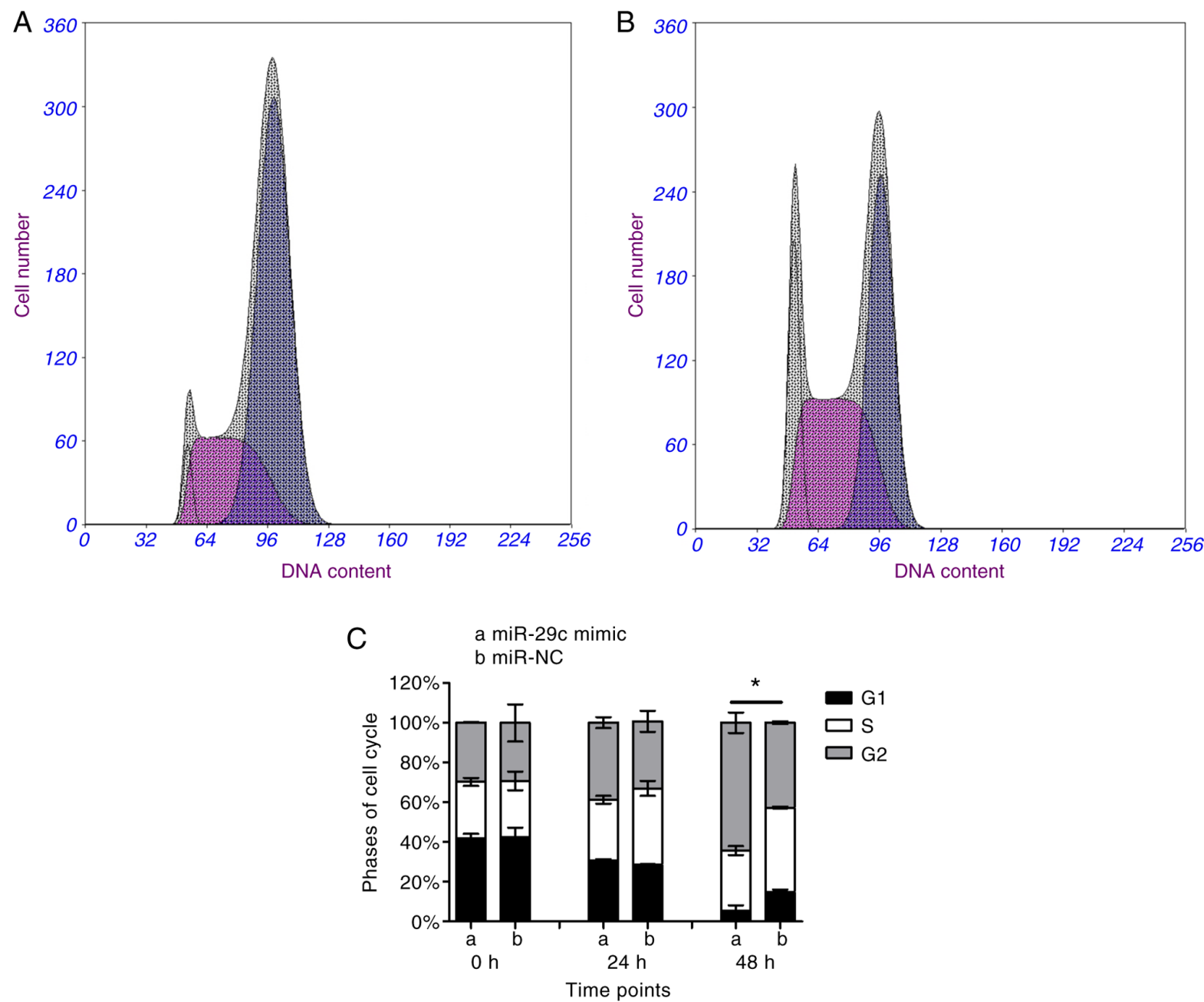

Figure 3. Flow cytometric assessment of cell cycle distribution. (A) miR-NC. (B) miR-29c-3p mimic group. In (A) and (B), the grey area represents $\mathrm{G}_{1}$ phase, the purple area represents $S$ phase and the blue area represents $G_{2}$ phase. (C) Cell cycle distribution $(n=3)$. ${ }^{2} P<0.05$ vs. miR-NC. miR, microRNA; NC, negative control.
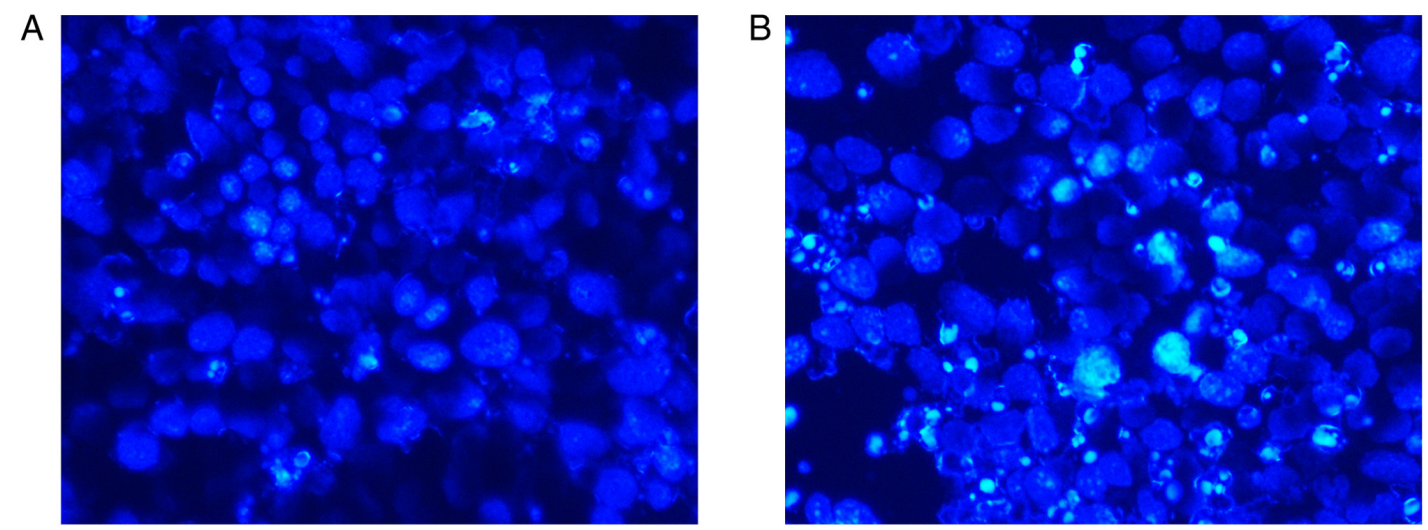

Figure 4. Effect of miR-29c-3p on cellular morphology detected using Hoechst staining under fluorescence microscopy (magnification, x200). (A) miR-29c-3p negative control group. (B) miR-29c-3p-overexpression group. miR, microRNA.

proportion of $\mathrm{S}$ phase cells in the Akt3-knockdown group in contrast with the control group (Fig. 10A, B and C).

The impact of Akt3 knockdown on the P19 cell apoptotic response was assessed by Hoechst staining, flow cytometry and the detection of apoptosis-associated genes. As presented in Fig. 11A and B, Akt3 knockdown increased cell apoptosis. Flow cytometry (Fig. 12A and B) also revealed that the knockdown of Akt3 significantly increased the apoptotic rate of P19 cells (Fig. 12C). Additionally, Akt3 knockdown decreased Bcl-2 mRNA expression and increased Bax protein expression in P19 cells compared with in control cells, indicating that Akt3 promotes P19 cell apoptosis; however, there was no difference in the expression of Bax mRNA and Bcl-2 protein between the two groups (Fig. 13A-C). 

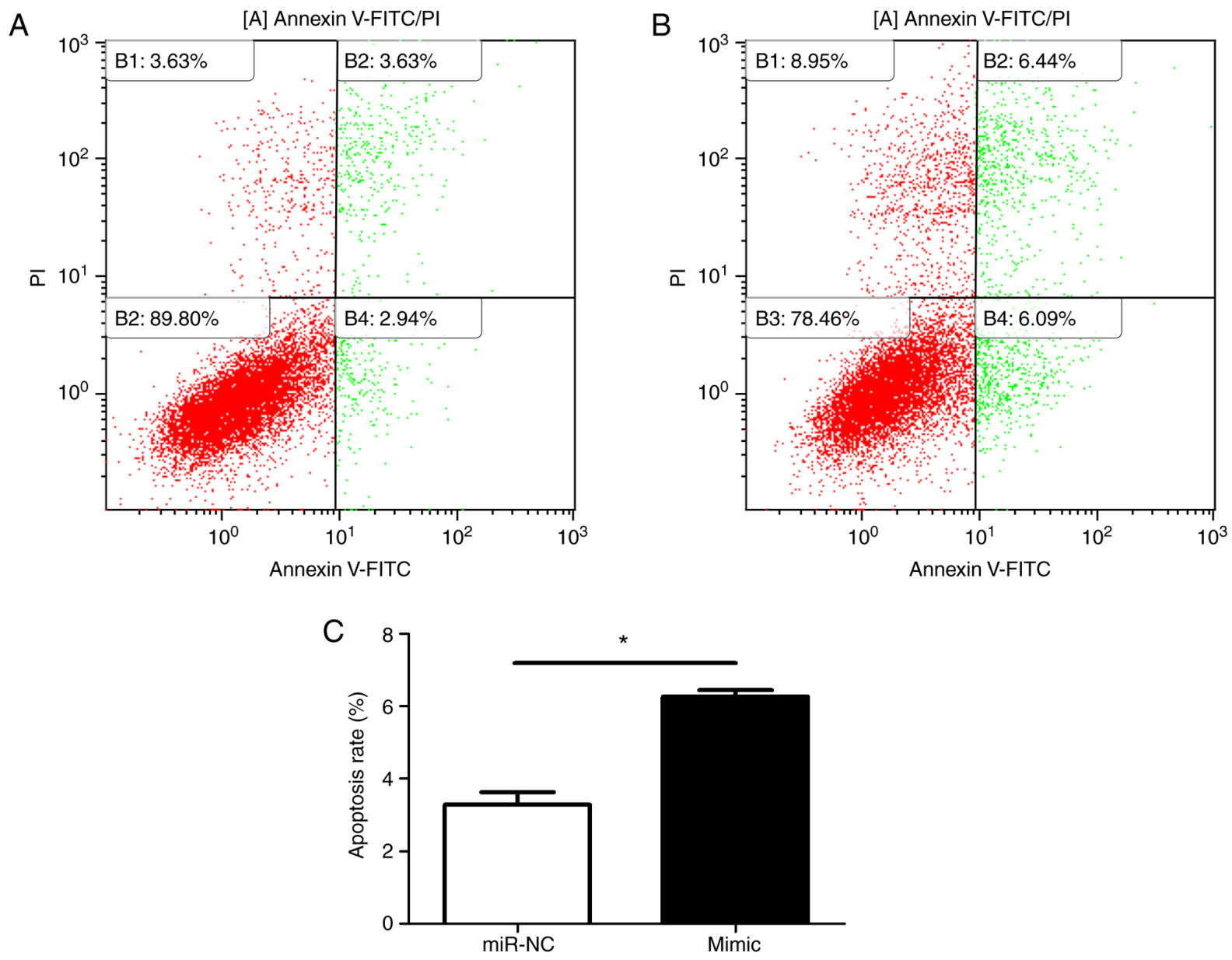

Figure 5. Apoptosis was assayed by the binding of PI/Annexin V-FITC. (A) miR-NC group. (B) miR-29c-3p mimic group. (C) Flow cytometry was used to assess the apoptotic rate $(n=3) .{ }^{*} \mathrm{P}<0.05$ vs. miR-NC. PI, propidium iodide; FITC, fluorescein isothiocyanate; miR, microRNA; NC, negative control.
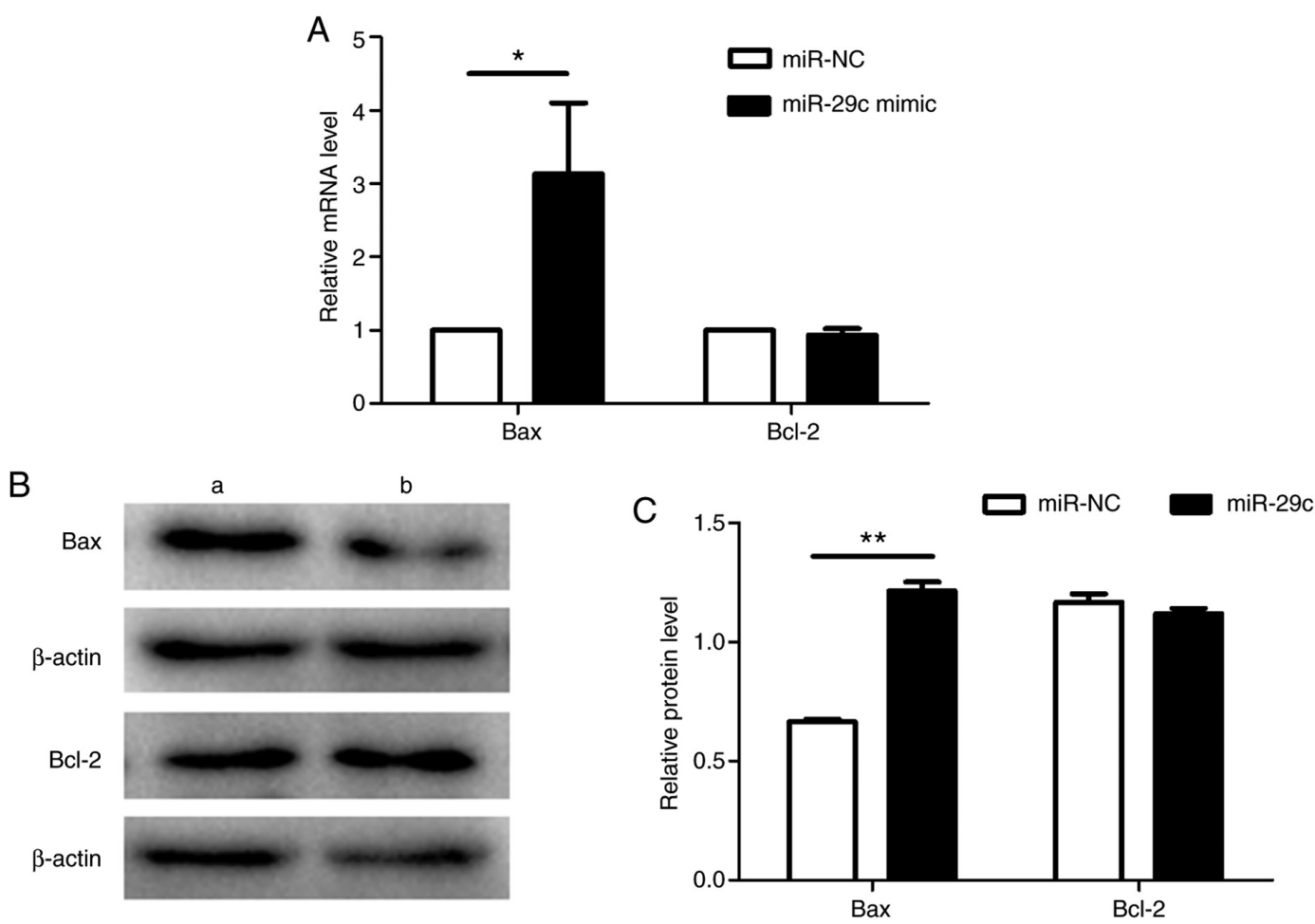

Figure 6. RT-qPCR and western blotting were used to detect the expression of apoptosis-associated genes and proteins. (A) RT-qPCR (n=3). ${ }^{*} \mathrm{P}<0.05$ vs. miR-NC. (B) Western blotting. a, miR-29c-3p mimic; b, miR-NC. (C) Quantification of the western blot analysis ( $\mathrm{n}=3$ ). ${ }^{* *} \mathrm{P}<0.01 \mathrm{vs}$. miR-NC. RT-qPCR, reverse transcription-quantitative polymerase chain reaction; miR, microRNA; NC, negative control; Bcl-2, B-cell lymphoma-2; Bax, Bcl-2-associated X protein. 


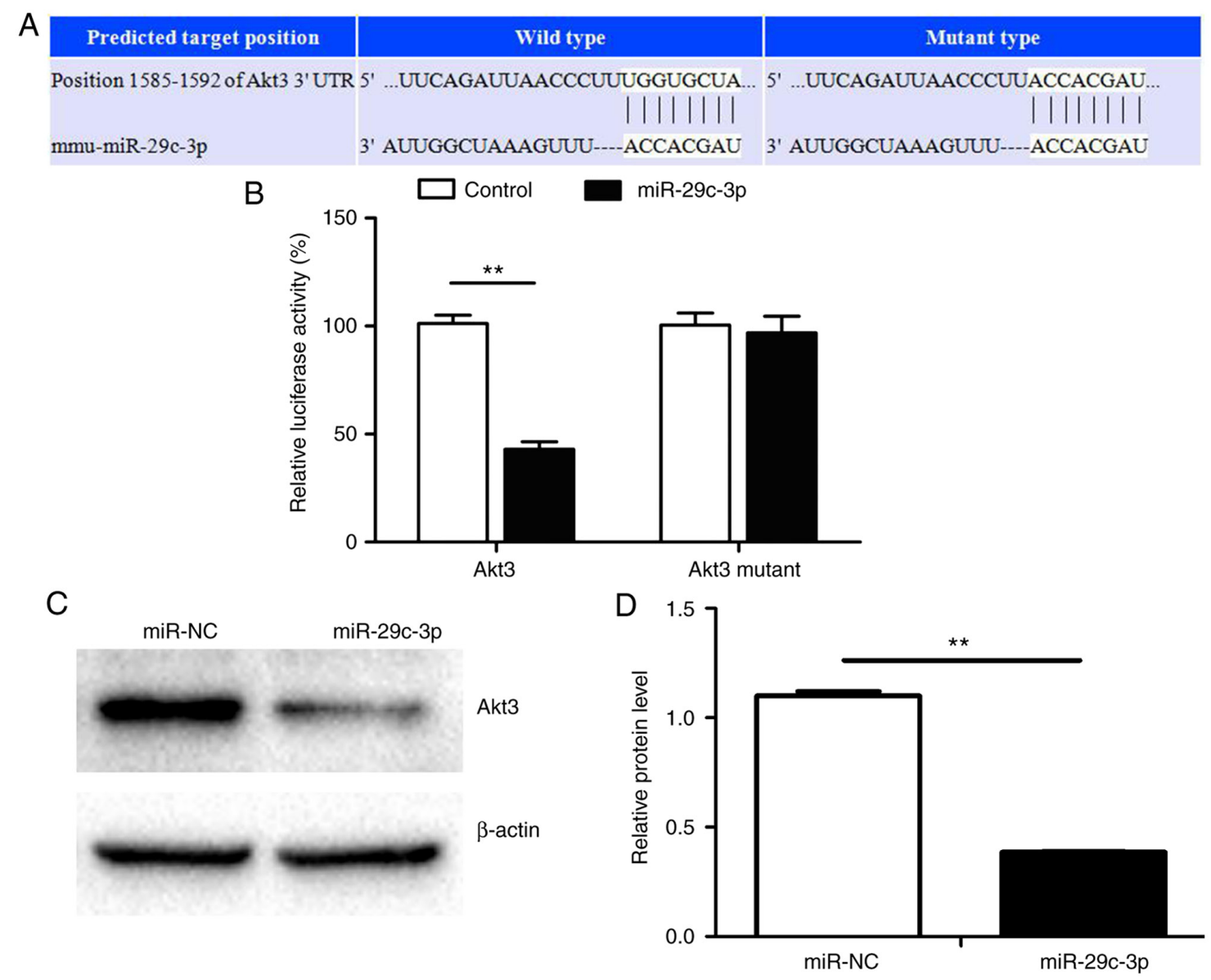

Figure 7. miR-29c-3p decreases Akt3 expression by targeting the Akt3 3'-UTR in P19 cells. (A) Subcloning of the predicted miR-29c-3p-3p-binding site at position 1585-1592 of the Akt3 3'-UTR into a luciferase construct. Predicted duplex formation between miR-29c-3p-3p and the wild-type or mutant miR-29c-3p-3p-binding site is indicated. (B) Luciferase reporter gene assay verification of the bioinformatics analysis. Akt3 was predicted as a target gene of miR-29c-3p ( $n=3){ }^{* *} \mathrm{P}<0.01$ vs. miR-NC. (C) Western blotting. (D) Protein expression of Akt3 in P19 cells with miR-29c-3p mimic (n=3). ${ }^{* * *} \mathrm{P}<0.01 \mathrm{vs}$. miR-NC. miR, microRNA; Akt3, protein kinase B $\gamma$; UTR, untranslated region; NC, negative control.

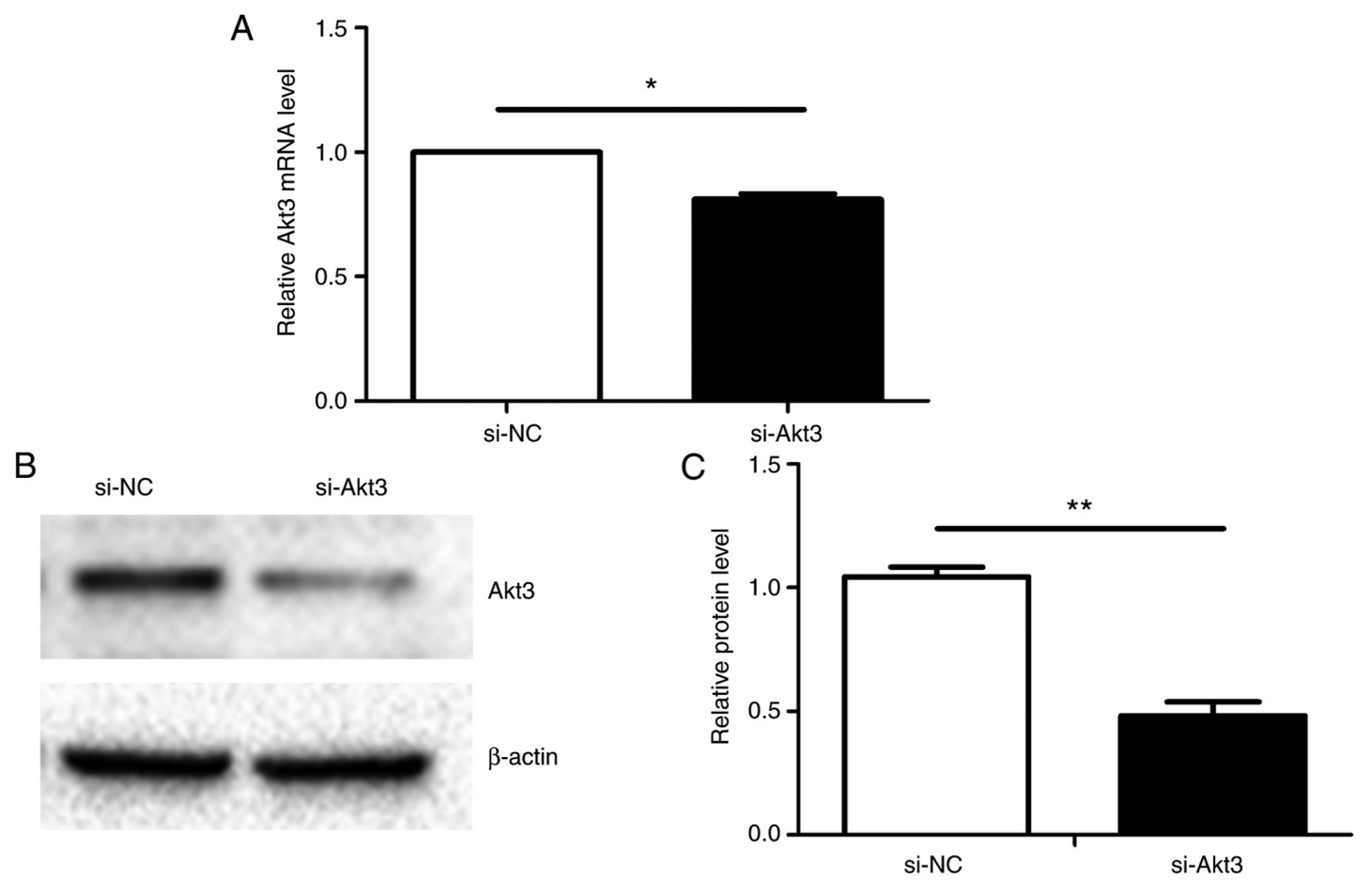

Figure 8. Transfection efficiency of si-Akt3. (A) Akt3 mRNA expression in P19 cells with si-Akt3 (n=3). "P<0.05 vs. si-NC. (B) Western blotting. (C) Akt3 protein expression in $\mathrm{P} 19$ cells with si-Akt3 $(\mathrm{n}=3)$. ${ }^{*} \mathrm{P}<0.05$ vs. si-NC. Akt3, protein kinase B $\gamma$; si, small interfering RNA; si-NC, siRNA negative control. 


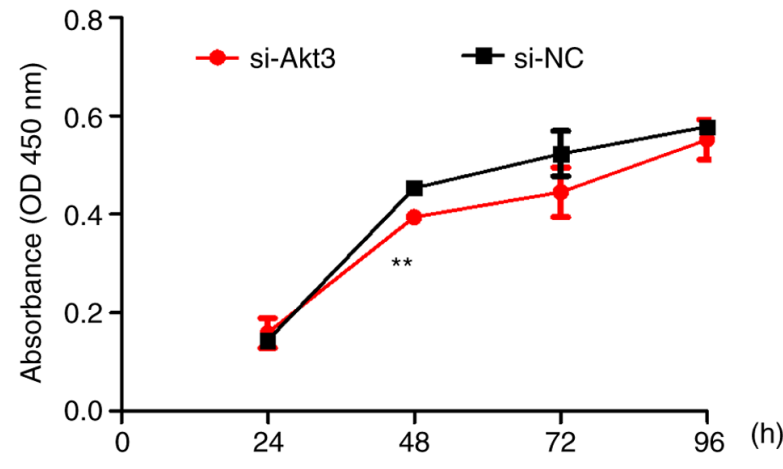

Figure 9. Cell proliferation was continuously monitored for $96 \mathrm{~h}$ in si-Akt3and si-NC-transfected $\mathrm{P} 19$ cells using the Cell Counting Kit- $8(\mathrm{n}=3) .{ }^{* *} \mathrm{P}<0.01$ vs. si-NC. Akt3, protein kinase $\mathrm{B} \gamma$; si, small interfering RNA; NC, negative control; OD, optical density.

miR-29c-3p promotes the differentiation of cardiomyocytes by decreasing Akt3 in P19 cells. The process by which P19 cells were induced into cardiomyocytes was observed using an inverted microscope. P19 cells underwent a series of morphological changes (Fig. 14). On day 4, cells in the miR-29c-3p-overexpression group and si-Akt 3 group formed more regular and larger EBs when cultured under the same conditions as the control group. Following transfer to 6-well culture plates on day 6 , cells in the miR-29c-3p-overexpression group and si-Akt3 group exhibited more uniform outward proliferation, centered on the EBs, whereas control group cells appeared more disordered. On day 8, beating cardiomyocytes were observed, but the miR-29c-3p-overexpression group and si-Akt 3 group cells were more active compared with those of the control group. On days $0,4,6,8$ and 10 of differentiation, relative mRNA expression of the myocardial-specific marker genes $\alpha \mathrm{MHC}$, Mef2c, GATA4 and cTnT was determined using RT-qPCR (Fig. 15A and B). Gene expression levels were significantly increased during the course of differentiation. In the miR-29c-3p-overexpression group and si-Akt3 group, the expression levels of these marker genes were increased compared with in controls.

\section{Discussion}

miRNAs have recently become a focus of research. Their main function is post-transcriptional gene regulation in plants and animals (32-34), and studies have increasingly focused on their function in heart development (35-37). We identified previously that $\mathrm{miR}-29 \mathrm{c}-3 \mathrm{p}$ is upregulated in the serum of pregnant women carrying fetuses with CHD (9).
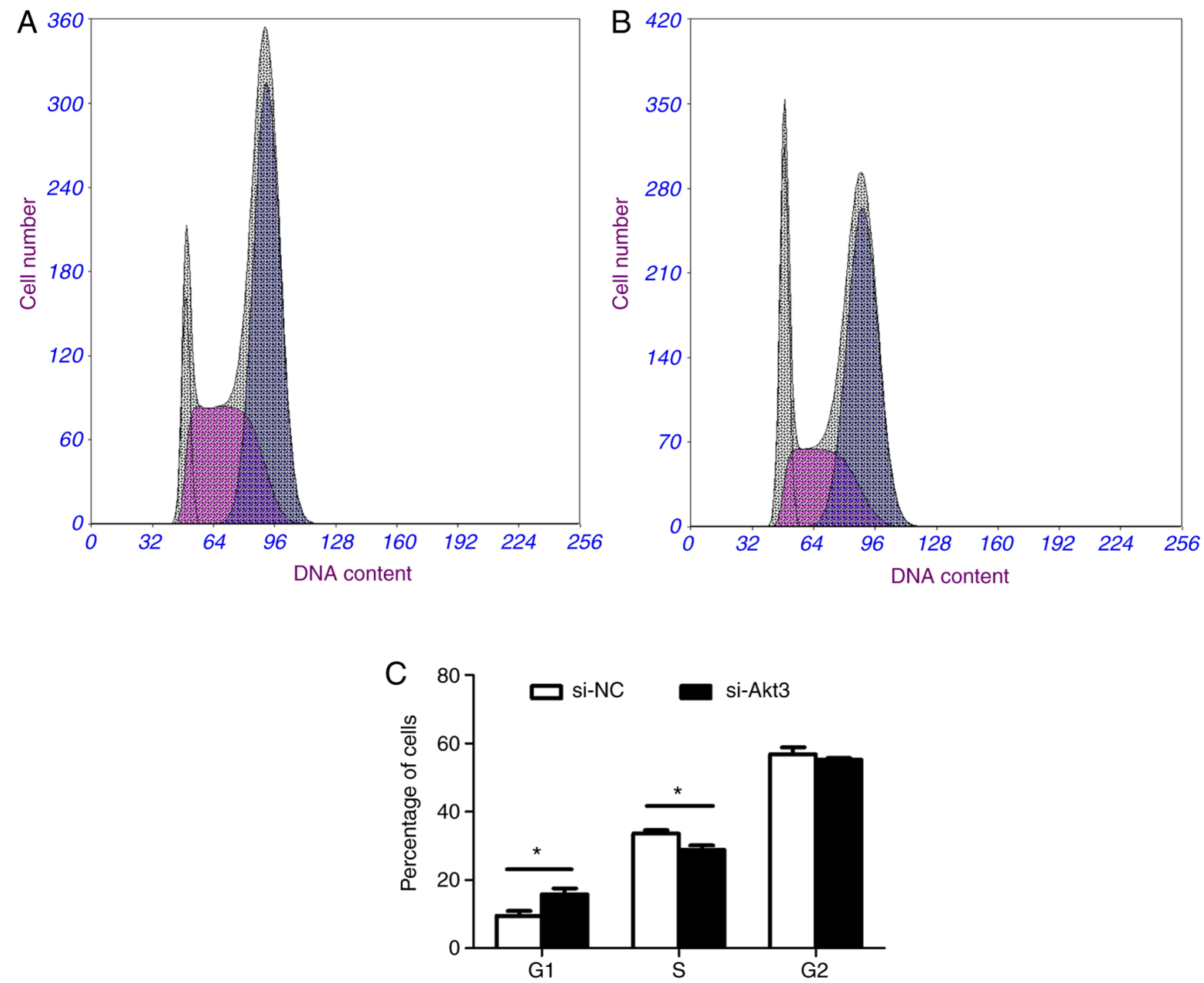

Figure 10. Flow cytometric assessment of cell cycle distribution at $48 \mathrm{~h}$. (A) si-NC group. (B) si-Akt 3 group. In (A) and (B) , the grey area represents $\mathrm{G}_{1}$ phase, the purple area represents $\mathrm{S}$ phase and the blue area represents $\mathrm{G}_{2}$ phase. $(\mathrm{C})$ Cell cycle distribution at $48 \mathrm{~h}(\mathrm{n}=3)$. $\mathrm{P}<0.05 \mathrm{vs}$. si-NC. Akt3, protein kinase $\mathrm{B} \gamma$; si, small interfering RNA; NC, negative control. 
A

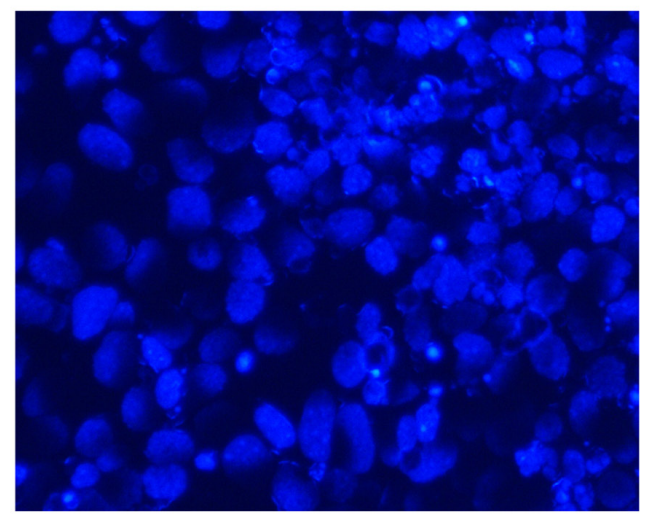

B

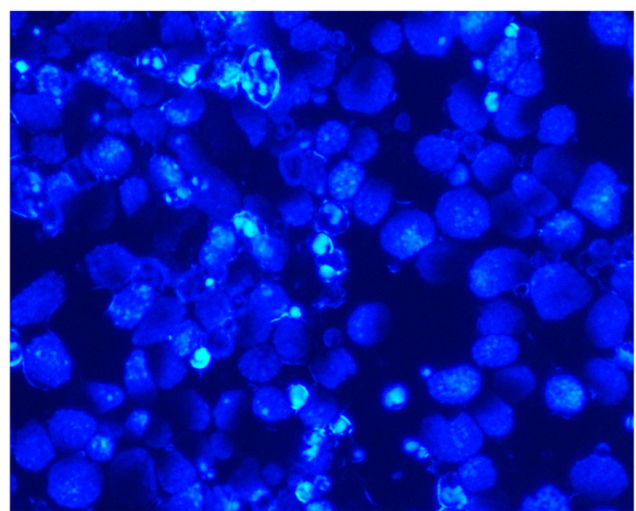

Figure 11. Effect of si-Akt3 on cellular morphology was detected using Hoechst staining under fluorescence microscopy (magnification, x200). (A) siRNA negative control group. (B) si-Akt3 group. si, small interfering RNA.

A

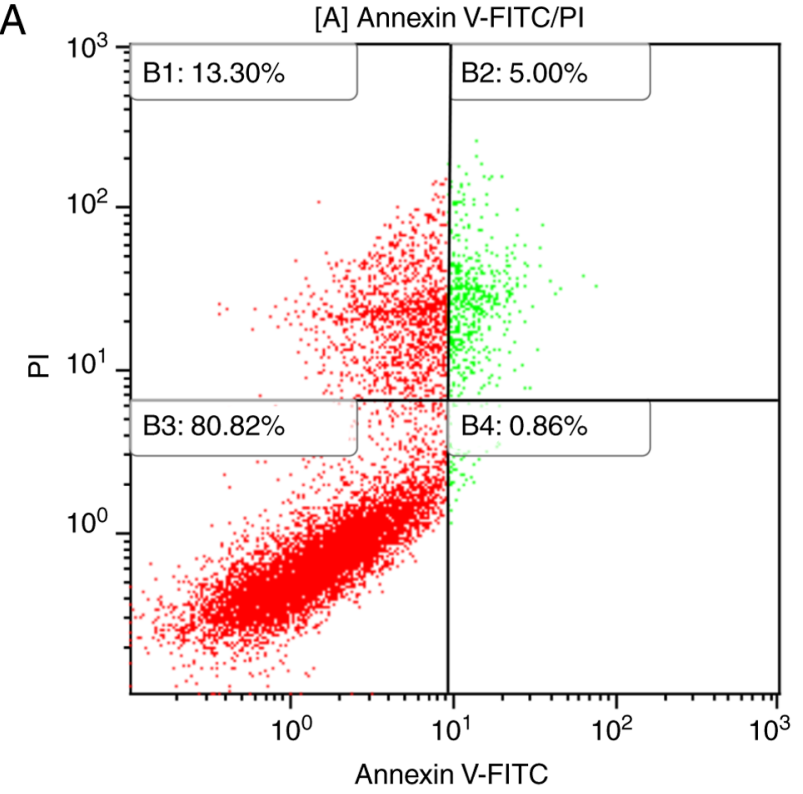

B

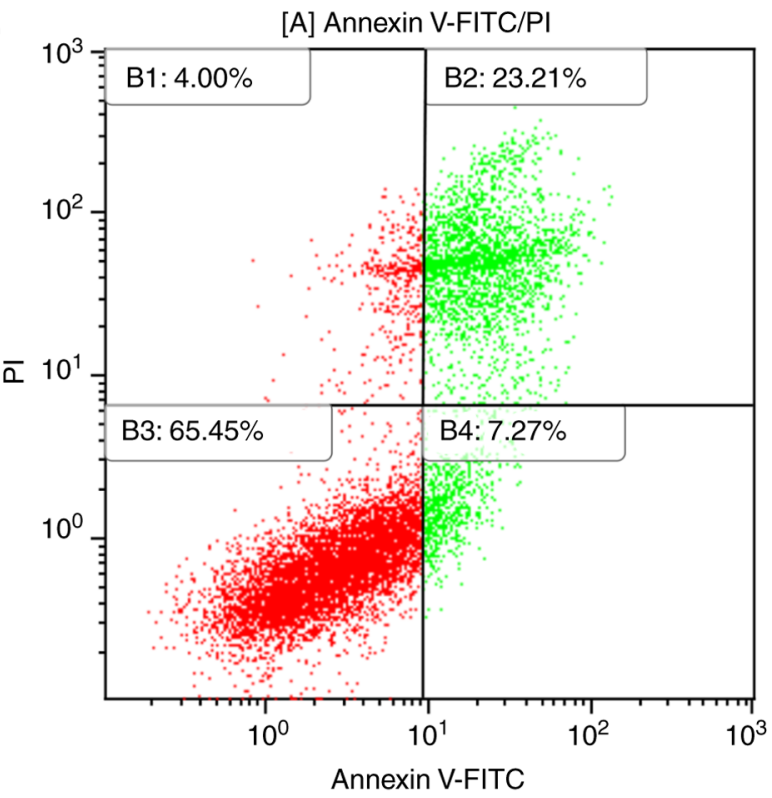

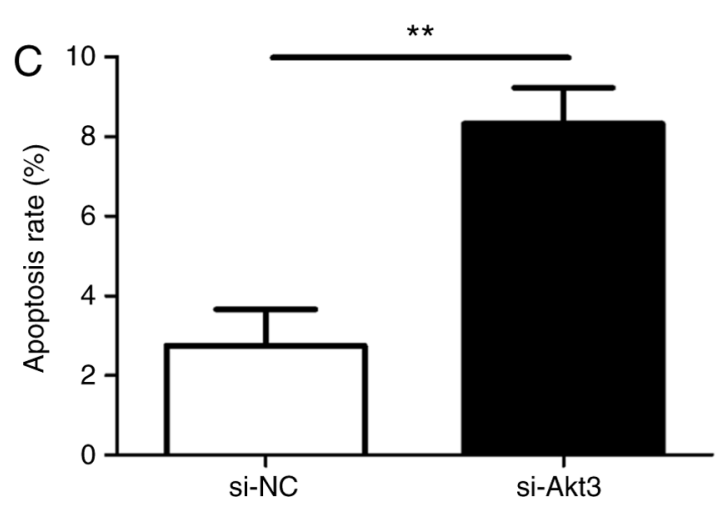

Figure 12. Apoptosis was assayed by the binding of PI/Annexin V-FITC. (A) si-NC group. (B) si-Akt3 group. (C) Flow cytometry was used to assess the apoptotic rate $(n=3) .{ }^{* *} \mathrm{P}<0.01$ vs. si-NC. PI, propidium iodide; FITC, fluorescein isothiocyanate; Akt3, protein kinase B $\gamma$; si, small interfering RNA; NC, negative control.

In the present study, the function of miR-29c-3p in cardiac development was investigated using transfection technology to simulate the internal environment of miR-29c-3p overexpression. miRNA mimics are a means of simulating and enhancing the function of endogenous miRNA (38), whereas miRNA inhibitors suppress the function of endogenous miRNAs (39).
In the present study, murine P19 cells were used to investigate cardiac cell differentiation and development. Following DMSO induction, P19 cells differentiate into beating cardiomyocytes. It was identified that miR-29c-3p overexpression suppressed proliferation, and promoted apoptosis and differentiation of P19 cells, and that Akt3 is a potential binding target of miR-29c-3p. 

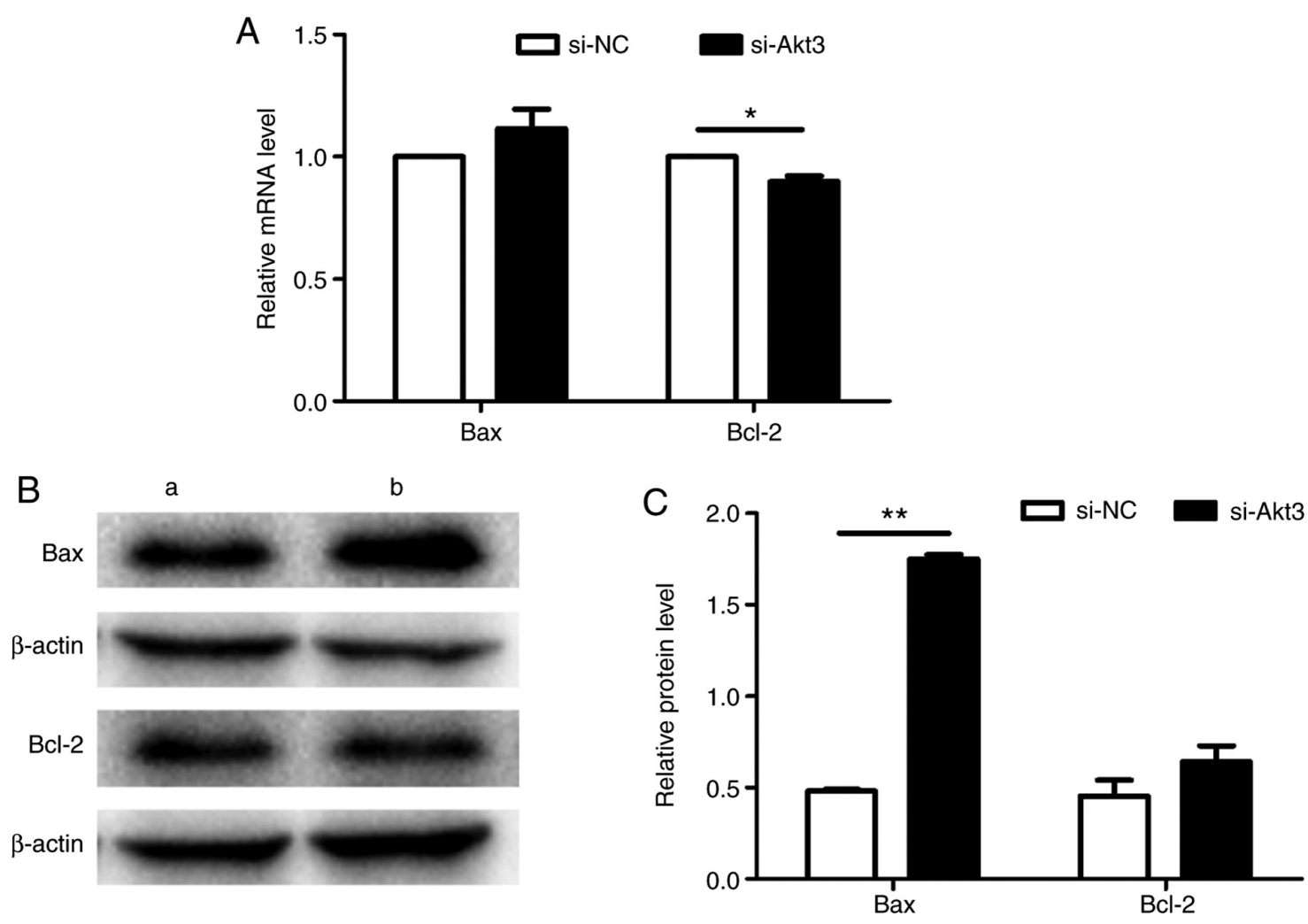

Figure 13. RT-qPCR and western blotting were used to detect the expression of apoptosis-associated genes and proteins. (A) RT-qPCR ( $\mathrm{n}=3$ ). ${ }^{*} \mathrm{P}<0.05$ vs. si-NC. (B) Western blotting. a, si-NC group; b, si-Akt3 group. (C) Quantification of the western blot analysis $(n=3){ }^{* *} \mathrm{P}<0.01$ vs. si-NC. RT-qPCR, reverse transcription-quantitative polymerase chain reaction; Akt3, protein kinase $\mathrm{B} \gamma$; si, small interfering RNA; NC, negative control.

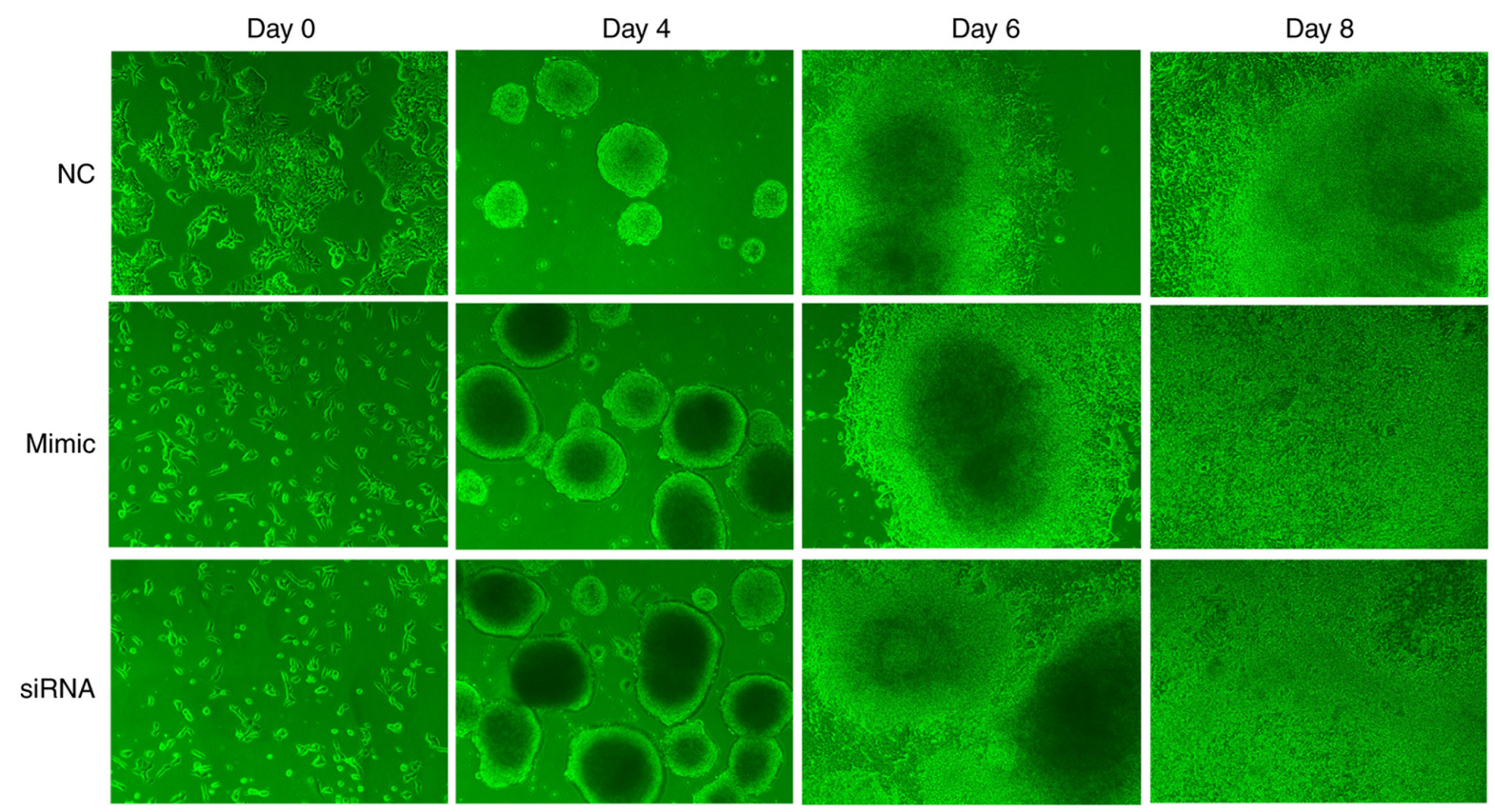

Figure 14. Micrographs presenting the morphological characteristics on days 0,4,6 and 8. Magnification, x100. NC, negative control; siRNA, small interfering RNA.

The proliferation curve indicated that the OD value of the miR-29c-3p-overexpression group was significantly lower compared with that of the control group at $72 \mathrm{~h}$ post-transfection, and similar results were obtained for the si-Akt 3 group at $48 \mathrm{~h}$. These results indicate that miR-29c-3p upregulation and Akt3 knockdown inhibit the proliferation of P19 cells. The differences between the two groups diminished following these time points, which may be due to cellular contact inhibition.

The formation of EBs is a key step in the process of P19 cell differentiation. Following DMSO induction, EBs were more regular and stable in the miR-29c-3p-overexpression group and si-Akt3 group compared with the control group. From day 4 

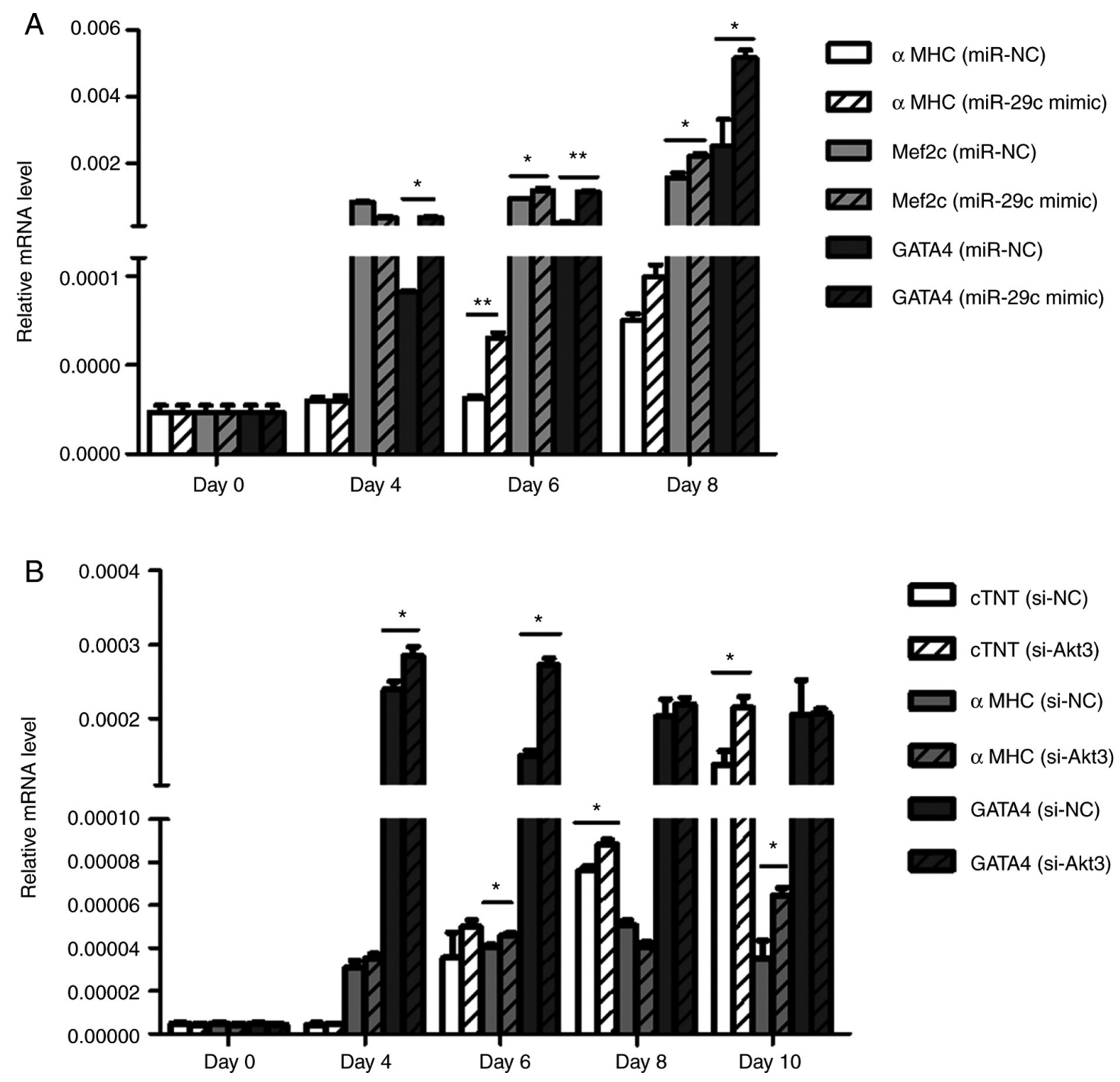

Figure 15. miR-29c-3p promotes the differentiation of cardiomyocytes via the decreased in Akt3 in P19 cells. (A) RT-qPCR analysis of relative $\alpha M H C$, Mef2c and GATA4 mRNA expression during differentiation between the miR-29c-3p-overexpression and control groups $(\mathrm{n}=3)$. ${ }^{*} \mathrm{P}<0.05$, ${ }^{* * *} \mathrm{P}<0.01$. (B) RT-qPCR analysis of relative cardiac $\alpha \mathrm{MHC}$, GATA4 and $\mathrm{cTnT}$ mRNA expression during differentiation between the si-Akt 3 and control groups $(\mathrm{n}=3)$. ${ }^{*} \mathrm{P}<0.05,{ }^{* *} \mathrm{P}<0.01$. RT-qPCR, reverse transcription-quantitative polymerase chain reaction; miR, microRNA; Akt3, protein kinase B $\gamma ; \alpha M H C, \alpha$-myosin heavy chain; Mef2c, myocyte enhancer factor 2c; GATA4, GATA-binding protein 4; cTNT, cardiac troponin T; si, small interfering RNA; NC; negative control.

of differentiation, the expression level of myocardium-specific marker genes was significantly increased compared with that in the control group, suggesting that miR-29c-3p upregulation and Akt 3 knockdown promote the differentiation of P19 cells into cardiomyocytes.

Infinite proliferation and universal differentiation are typical characteristics of embryonal carcinoma cells. During proliferation, cells proliferate at a certain density, whereas pluripotent stem cells transform into different tissues in the differentiation process (40). These features enable P19 cells to transform into cardiomyocytes and develop into beating hearts. The results of the present study revealed that miR-29c-3p overexpression and Akt3 knockdown inhibit proliferation and promote the differentiation of P19 cells. This contributes to inefficiency and imbalance in embryonic heart development, which is why miR-29c-3p overexpression appears to be associated with CHD.

Cardiac morphogenesis is a complex process, during which the heart develops from a simple tube into a structure with four cavities and a separate outflow tract (41-43). During this process, a number of specific structures emerge and disappear, and apoptosis serves a crucial function. Apoptotic cells stained with Hoechst dye emit fluorescence which may be observed under a fluorescent microscope. Furthermore, the apoptotic cell nucleus is lobulated, fragmented and light blue, compared with the round blue normal nucleus with dark blue grains. In the present study, significantly more apoptotic cells were observed in the miR-29c-3p-overexpression group and si-Akt 3 group compared with in the control group after $48 \mathrm{~h}$. This observation was confirmed by flow cytometry. The apoptotic rate of the miR-29c-3p-overexpression group and si-Akt3 group was also significantly increased compared with that in the control group.

The Bcl family is one of a number of gene families regulating apoptosis $(44,45)$. Bcl-2 and Bax are members of this family, but have opposing functions, with $\mathrm{Bcl}-2$ inhibiting apoptosis and Bax promoting it. Together, they regulate the internal balance of apoptosis with other family 
members (46). Increased gene expression of Bax was observed in the miR-29c-3p-overexpression group compared with in the control group, and decreased gene expression of Bcl-2 was observed in the si-Akt3 group compared with in the control group. Therefore, the pro-apoptotic effect of miR-29c-3p on P19 cells may be due to the regulation of apoptosis-associated genes.

Previous studies have identified that Akt3 transgenic mice have notable cardiac hypertrophy, suggesting that a potential function of Akt3 is to promote cardiomyocyte proliferation. Cardiac growth at 4 weeks of age was also identified to resemble compensated hypertrophy, whereas hypertrophy at 20 weeks of age was clearly pathological on the basis of measurements of interstitial fibrosis and cardiac performance (17). In the early embryo, the Akt 3 signal is beneficial for cardiac growth; however, the sustained activation of Akt3 signaling may have adverse effects and result in maladaptive hypertrophy. The results of the present study indicate that Akt3 is a target of $\operatorname{miR}-29 c-3 p$, and that the overexpression of miR-29c-3p decreases Akt3 expression levels. Taken together, these results suggested that regulating Akt3 expression may be one of the ways in which miR-29c-3p affects cardiac development.

The results of the present study revealed that miR-29c-3p overexpression decreases proliferation, and promotes apoptosis and differentiation in P19 cells. The underlying molecular mechanism may involve regulation of the miR-29c-3p target gene Akt3. These results may contribute to an improved understanding of heart development, and may assist in preventing the development of CHD and other serious cardiac disorders.

\section{Acknowledgements}

We thank Dr Sarah Williams for editing the English text of a draft of this manuscript.

\section{Funding}

The present study was supported by the Maternal and Child Health Research Project of Jiangsu Province (grant no. F201509) and National Natural Science Foundation of China (grant no. 81573234).

\section{Availability of data and materials}

The datasets used and/or analyzed during the current study are available from the corresponding author on reasonable request.

\section{Authors' contributions}

TC and SJL performed the major examination, TC was a major contributor in writing the manuscript. BC, QH, XYK and CS analyzed the data of this study. HTG made substantial contributions to the conception and design of the study, acquisition of data, analysis and interpretation of data. XWW revised the paper critically for important intellectual content. All authors read and approved the final manuscript.

\section{Ethics approval and consent to participate}

Not applicable.

\section{Patient consent for publication}

Not applicable.

\section{Competing interests}

The authors declare that they have no competing interests.

\section{References}

1. Wang $\mathbf{J}$ and Liu B: Exercise and congenital heart disease. Adv Exp Med Biol 1000: 95-101, 2017.

2. Junghare SW and Desurkar V: Congenital heart diseases and anaesthesia. Indian J Anaesth 61: 744-752, 2017.

3. Itani M, Matesan M, Ahuja J, Bermo M, Habib AS, Goiney C, Krieger EV and Vesselle $\mathrm{H}$ : The role of pulmonary scintigraphy in the evaluation of adults with congenital heart disease. Semin Nucl Med 47: 660-670, 2017.

4. Suradi HS and Hijazi ZM: Adult congenital interventions in heart failure. Interv Cardiol Clin 6: 427-443, 2017.

5. Chien PS, Chiang $C B$ and Wang $Z$ and Chiou TJ: MicroRNA-mediated signaling and regulation of nutrient transport and utilization. Curr Opin Plant Biol 39: 73-79, 2017.

6. de Lucia C, Komici K, Borghetti G, Femminella GD, Bencivenga L, Cannavo A, Corbi G, Ferrara N, Houser SR, Koch WJ and Rengo G: microRNA in cardiovascular aging and age-related cardiovascular diseases. Front Med (Lausanne) 4: 74, 2017.

7. Stanley-Hasnain S, Hauck L, Grothe D and Billia F: Control of cardiomyocyte proliferation through $\mathrm{p} 53 / \mathrm{Mdm} 2$-regulated MicroRNAs. J Heart Lung Transpl 35 (Suppl 1): S183-S184, 2016.

8. Zhou Y, Jia WK, Jian Z, Zhao L, Liu CC, Wang Y and Xiao YB: Downregulation of microRNA-199a-5p protects cardiomyocytes in cyanotic congenital heart disease by attenuating endoplasmic reticulum stress. Mol Med Rep 16: 2992-3000, 2017.

9. Zhu S, Cao L, Zhu J, Kong L, Jin J, Qian L, Zhu C, Hu X, Li M, Guo X, et al: Identification of maternal serum MicroRNAs as novel noninvasive biomarkers for prenatal detection of fetal congenital heart defects. Clin Chim Acta 424: 66-72, 2013.

10. Shu YJ, Bao RF, Jiang L, Wang Z, Wang XA, Zhang F, Liang HB, Li HF, Ye YY, Xiang SS, et al: MicroRNA-29c-5p suppresses gallbladder carcinoma progression by directly targeting CPEB4 and inhibiting the MAPK pathway. Cell Death Differ 24: 445-457, 2017.

11. Han TS, Hur K, Xu G, Choi B, Okugawa Y, Toiyama Y, Oshima H, Oshima M, Lee HJ, Kim VN, et al: MicroRNA-29c mediates initiation of gastric carcinogenesis by directly targeting ITGB1. Gut 64: 203-214, 2015.

12. Zhang HW, Wang EW, Li LX, Yi SH, Li LC, Xu FL, Wang DL, Wu YZ and Nian WQ: A regulatory loop involving miR-29c and Sp1 elevates the TGF- $\beta 1$ mediated epithelial-to-mesenchymal transition in lung cancer. Oncotarget 7: 85905-85916, 2016.

13. Niu M, Gao D, Wen Q, Wei P, Pan S, Shuai C, Ma H, Xiang J, Li Z, Fan S, et al: MiR-29c regulates the expression of miR-34c and miR-449a by targeting DNA methyltransferase 3a and $3 \mathrm{~b}$ in nasopharyngeal carcinoma. BMC Cancer 16: 218, 2016.

14. Butrym A, Rybka J, Baczyńska D, Poręba R, Kuliczkowski K and Mazur G: Clinical response to azacitidine therapy depends on microRNA-29c (miR-29c) expression in older acute myeloid leukemia (AML) patients. Oncotarget 7: 30250-30257, 2016.

15. Nygren MK, Tekle C, Ingebrigtsen VA, Mäkelä R, Krohn M, Aure MR, Nunes-Xavier CE, Perälä M, Tramm T, Alsner J, et al: Identifying microRNAs regulating $\mathrm{B} 7-\mathrm{H} 3$ in breast cancer: The clinical impact of microRNA-29c. Br J Cancer 110: 2072-2080, 2014.

16. Wang S, Zhu Y and Qiu R: Shikonin protects H9C2 cardiomyocytes against hypoxia/reoxygenation injury through activation of PI3K/Akt signaling pathway. Biomed Pharmacother 104: 712-717, 2018.

17. Taniyama Y, Ito M, Sato K, Kuester C, Veit K, Tremp G, Liao R, Colucci WS, Ivashchenko Y, Walsh K and Shiojima I: Akt3 overexpression in the heart results in progression from adaptive to maladaptive hypertrophy. J Mol Cell Cardiol 38: 375-385, 2005.

18. Shiojima I, Sato K, Izumiya Y, Schiekofer S, Ito M, Liao R, Colucci WS and Walsh K: Disruption of coordinated cardiac hypertrophy and angiogenesis contributes to the transition to heart failure. J Clin Invest 115: 2108-2118, 2005. 
19. Yoshioka K, Yoshida K, Cui H, Wakayama T, Takuwa N, Okamoto Y, Du W, Qi X, Asanuma K, Sugihara K, et al: Endothelial PI3K-C2 $\alpha$, a class II PI3K, has an essential role in angiogenesis and vascular barrier function. Net Med 18: 1560-1569, 2012.

20. Kanungo J: Retinoic acid signaling in P19 stem cell differentiation. Anticancer Agents Med Chem 17: 1184-1198, 2017.

21. Wang L, Song G, Liu M, Chen B, Chen Y, Shen Y, Zhu J and Zhou X: MicroRNA-375 overexpression influences P19 cell proliferation, apoptosis and differentiation through the notch signaling pathway. Int J Mol Med 37: 47-55, 2016.

22. McBurney MW, Jones-Villeneuve EM, Edwards MK and Anderson PJ: Control of muscle and neuronal differentiation in a cultured embryonal carcinoma cell line. Nature 299: 165-167, 1982.

23. Mueller I, Kobayashi R, Nakajima T, Ishii M and Ogawa K: Effective and steady differentiation of a clonal derivative of P19CL6 embryonal carcinoma cell line into beating cardiomyocytes. J Biomed Biotechnol 2010: 380561, 2010.

24. Song G, Shen Y, Ruan Z, Li X, Chen Y, Yuan W, Ding X, Zhu L and Qian L: LncRNA-uc.167 influences cell proliferation, apoptosis and differentiation of P19 cells by regulating Mef2c. Gene 590: 97-108, 2016.

25. van der Heyden MA and Defize LH: Twenty one years of P19 cells: What an embryonal carcinoma cell line taught us about cardiomyocyte differentiation. Cardiovasc Res 58: 292-302, 2003.

26. Mcburney MW: P19 embryonal carcinoma cells. Int J Dev Biol 37: 135-140, 1993.

27. Ai F, Zhang Y and Peng B: miR-20a regulates proliferation, differentiation and apoptosis in P19 cell model of cardiac differentiation by targeting smoothened. Biol Open 5: 1260-1265, 2016

28. Wang D, Liu C, Wang Y, Wang W, Wang K, Wu X, Li Z, Zhao C, $\mathrm{Li} \mathrm{L}$ and Peng L: Impact of miR-26b on cardiomyocyte differentiation in P19 cells through regulating canonical/non-canonica wnt signaling. Cell Proliferation 50: e12371, 2017.

29. Li H, Jiang L, Yu Z, Han S, Liu X, Li M, Zhu C, Qiao L and Huang L: The role of a novel long noncoding RNA TUC40- in cardiomyocyte induction and maturation in P19 cells. Am J Med Sci 354: 608-616, 2017.

30. Van Poucke M, Van Zeveren A and Peelman LJ: [Letter to the editor] Combined FAM-labeled TaqMan probe detection and SYBR green I melting curve analysis in multiprobe qPCR genotyping assays. Biotechniques 52: 81-86, 2012.

31. Wang J, Meng X, Dobrovolskaya OB, Orlov YL and Chen M: Non-coding RNAs and their roles in stress response in plants. Genomics Proteomics Bioinformatics 15: 301-312, 2017.

32. Livak KJ and Schmittgen TD: Analysis of relative gene expression data using real-time quantitative PCR and the 2(-Delta Delta C(T)) method. Methods 25: 402-408, 2001
33. Grossi I, Salvi A, Abeni E, Marchina E and De Petro G: Biological function of MicroRNA193a-3p in health and disease. Int J Genomics 2017: 5913195, 2017.

34. Kumar V, Khare T, Shriram V and Wani SH: Plant small RNAs: The essential epigenetic regulators of gene expression for salt-stress responses and tolerance. Plant Cell Rep 37: 61-75, 2018.

35. Chen C, Ponnusamy M, Liu C, Gao J, Wang K and Li P. MicroRNA as a therapeutic target in cardiac remodeling. Biomed Res Int 2017: 1278436, 2017.

36. Wojciechowska A, Braniewska A and Kozar-Kamińska K MicroRNA in cardiovascular biology and disease. Adv Clin Exp Med 26: 865-874, 2017.

37. Sun W, Zhao L, Song X, Zhang J, Xing Y, Liu N, Yan Y, $\mathrm{Li} \mathrm{Z,} \mathrm{Lu} \mathrm{Y,} \mathrm{Wu} \mathrm{J,} \mathrm{et} \mathrm{al:} \mathrm{MicroRNA-210} \mathrm{modulates} \mathrm{the} \mathrm{cellular}$ energy metabolism shift during $\mathrm{H} 2 \mathrm{O} 2$-induced oxidative stress by repressing ISCU in H9c2 cardiomyocytes. Cell Physiol Biochem 43: 383-394, 2017.

38. Chu D, Zhao Z, Li Y, Li J, Zheng J, Wang W, Zhao Q and $\mathrm{Ji}$ G: Increased microRNA-630 expression in gastric cancer is associated with poor overall survival. PLoS One 9: e90526, 2014.

39. Qiao P, Li G, Bi W, Yang L, Yao L and Wu D: microRNA-34a inhibits epithelial mesenchymal transition in human cholangiocarcinoma by targeting Smad4 through transforming growth factor-beta/Smad pathway. BMC Cancer 15: 469, 2015.

40. Rijlaarsdam MA and Looijenga LH: An oncofetal and developmental perspective on testicular germ cell cancer. Semin Cancer Biol 29: 59-74, 2014.

41. Paraskevas G, Koutsouflianiotis K and Iliou K: The first descriptions of various anatomical structures and embryological remnants of the heart: A systematic overview. Int J Cardiol 227: 674-690, 2017.

42. Gittenbergerde Groot AC, Bartelings MM, Poelmann RE, Haak MC and Jongbloed MR: Embryology of the heart and its impact on understanding fetal and neonatal heart disease. Semin Fetal Neonatal Med 18: 237-244, 2013.

43. Abu-Elmagd $M$ and Wheeler G: Frizzled-7 expression during early cardiogenesis of Xenopus laevis embryo. BMC Genomics 15: 1-2, 2014.

44. Vitagliano $\mathrm{O}$, Addeo R, D'Angelo $\mathrm{V}$, Indolfi $\mathrm{C}$, Indolfi $\mathrm{P}$ and Casale F: The Bcl-2/Bax and Ras/Raf/MEK/ERK signaling pathways: Implications in pediatric leukemia pathogenesis and new prospects for therapeutic approaches. Expert Rev Hematol 6: 587-597, 2013.

45. Siddiqui WA, Ahad A and Ahsan H: The mystery of BCL2 family: Bcl-2 proteins and apoptosis: An update. Arch Toxicol 89: 289-317, 2015.

46. Reed JC: Proapoptotic multidomain Bcl-2/Bax-family proteins: Mechanisms, physiological roles, and therapeutic opportunities. Cell Death Differ 13: 1378-1386, 2006. 